Check for updates

Cite this: RSC Adv., 2017, 7, 44505

Received 15th July 2017

Accepted 9th September 2017

DOI: $10.1039 / c 7 r a 07783 a$

rsc.li/rsc-advances

\section{Bioinspired fabrication of macroporous calcium
carbonate crystals mediated by thermoresponsive \\ Bioinspired fabrication of macroporous calcium
carbonate crystals mediated by thermoresponsive copolymers $\uparrow$}

\author{
Siyu Shi, Long Cai, Xue Liu, Haonan Li, Yuan Gao, Qiuhua Wu, ${ }^{\star}$ Jie Yi, Ximing Song \\ and Guolin Zhang (iD *
}

A new thermoresponsive copolymer, poly( $N$-vinylcaprolactam)- $\beta$-cyclodextrin (PNVCL- $\beta$-CD), was synthesized by click chemistry and applied in regulating the crystallization of $\mathrm{CaCO}_{3}$. At low temperature $\left(25^{\circ} \mathrm{C}\right.$ ), the copolymers self-assembled into micelles with $\beta-C D$ as the core and PNVCL as the shell. The micelles with different PNVCL chain lengths induced the formation of crystals with elongated, typical rhombohedral and surface concaved morphologies. At high temperature $\left(50{ }^{\circ} \mathrm{C}\right)$, the micelles assembled into compact and regular aggregates with sizes of about $1 \mu \mathrm{m}$. The copolymer aggregates were encapsulated in the crystals and removed after cooling and rinsing. Porous, cheese-like crystals were obtained. This study could enrich our knowledge of biomineralization and offer a convenient scheme for synthesis of porous inorganic materials.

\section{Introduction}

Biominerals with specific structures and fascinating morphologies widely exist in nature as bones, teeth, shells, corals and magnetic crystals in bacteria. ${ }^{1-5}$ They are usually prepared at room temperature in an aqueous environment, and exhibit remarkable mechanical strength with excellent toughness. ${ }^{1,6}$ Inspired by these biominerals, the biomimetic synthesis of inorganic materials with specific size, morphology, and superstructure has attracted considerable attention due to the obvious importance of the shape and texture of the materials in determining their properties. ${ }^{1,7,8}$ Through this process, a small amount of organic material binds to the crystal face and controls the crystal growth; the resulting biominerals possess highly controlled shapes and sizes under ambient conditions. ${ }^{6,9-11}$ Compared with the size control, the morphology control is more difficult to achieve by means of classical procedures. $^{12}$

One of the most intensely investigated systems is calcium carbonate $\left(\mathrm{CaCO}_{3}\right)$, which is the most abundant biominerals in nature, ${ }^{13}$ but also of industrial importance due to its wide use as raw material in paints, plastics, rubber, or paper.,12,14-16 Many materials including Langmuir monolayers, ${ }^{17,18}$ self-assembled monomolecular (SAM) films, ${ }^{19}$ and crosslinked gelatin films ${ }^{20}$

Liaoning Province Key Laboratory for Green Synthesis and Preparative Chemistry of Advanced Materials (Liaoning University), College of Chemistry, Liaoning University, Shenyang 110036, People's Republic of China. E-mail: qiuhuawu@sina.com; glzhang@lnu.edu.cn

$\dagger$ Electronic supplementary information (ESI) available. See DOI: 10.1039/c7ra07783a have been employed as effective additives or templates to induce the controlled growth of $\mathrm{CaCO}_{3}$ crystals. Moreover, a variety of macromolecular additives, including biopolymers, ${ }^{21,22}$ double hydrophilic block copolymers, ${ }^{2}$ polyelectrolytes, ${ }^{23,24}$ designed peptides ${ }^{25}$ and dendrimers, ${ }^{1}$ have exhibited effective control of morphology, polymorphs and then properties. ${ }^{26-28}$ For example, the optical and magnetic functionalizing calcite single crystals were prepared through nanoparticle incorporation inside the single crystals by Li group. ${ }^{29}$

In recent years, porous inorganic materials such as porous $\mathrm{CaCO}_{3}$ have been extensively studied for their important applications as catalyst supports, ceramics, paints, as well as novel biomimetic scaffolds for target drug delivery, bioimaging and tissue engineering. ${ }^{30-32}$ According to the IUPAC defined pore dimensions, porous materials are classified as microporous, mesoporous and macroporous structures, with the corresponding pore sizes of $<2 \mathrm{~nm}, 2-50 \mathrm{~nm}$ and $>50 \mathrm{~nm}$, respectively. ${ }^{33}$

For example, porous vaterite could be prepared in the presence several food grade polymeric modifier; ${ }^{34}$ well-defined calcite single crystals exhibiting a rhombohedral morphology and uniform surface pores are synthesized by using monodispersed copolymer latex particles as effective colloidal templates and following removal of templates; ${ }^{23}$ porous single crystals of calcite with inverse opal and direct opal structures are prepared using templates of colloidal crystals and polystyrene reverse opals, respectively; ${ }^{35}$ macroporous single crystals of calcite with controlled orientation and well-defined nanopatterns can be produced by combination of the amorphous-to-crystalline strategy and the colloidal crystal templating method. ${ }^{36}$ Compared with other porous inorganic materials, porous $\mathrm{CaCO}_{3}$ particles have been less studied though they are non-toxic and 
the synthesis of $\mathrm{CaCO}_{3}$ is cost-effective and does not need the use of any organic solvents. ${ }^{28}$

In order to induce the formation of pores in $\mathrm{CaCO}_{3}$ crystals, we designed a new copolymer porogenic agent, $\operatorname{poly}(N$-vinylcaprolactam)- $\beta$-cyclodextrin $\quad$ (PNVCL- $\beta$-CD). Poly $(N$-vinylcaprolactam) (PNVCL) is a typical thermoresponsive polymer with a lower critical solution temperature (LCST) near body temperature in aqueous environment. ${ }^{37-41} \quad \beta$-Cyclodextrin $(\beta-\mathrm{CD})$ is a cyclic oligosaccharide, which is a truncated conical molecule with a hydrophobic interior and two hydrophilic rims, and has a hollow cavity constituted by seven D-glucopyranose units. ${ }^{42}$ The PNVCL- $\beta$-CD copolymer can self-assemble into micelles below the LCST and form compact aggregates above the LCST. The influences of the micelles and compact aggregates on the crystallization of $\mathrm{CaCO}_{3}$ were studied respectively. The results showed the micelles induced the formation of crystals with various morphologies, while the compact aggregates induced the formation of macroporous cheese-like crystals. By a series of control experiments and time-resolved experiments, the possible mechanisms were proposed.

\section{Experimental sections}

\subsection{Materials}

$N$-Vinylcaprolactam (NVCL) was purchased from Sigma-Aldrich and recrystallized from dry $n$-hexane prior to use. $p$-Toluenesulfonyl chloride ( $\mathrm{TsCl}$, chemical reagent) was purchased from Sinopharm Chemical Reagent Co., Ltd. (Shanghai, China) and recrystallized in the mixed solvents of chloroform and $n$-hexane before use. Azobisisobutyronitrile (AIBN) was purchased from Sinopharm Chemical Reagent Co., Ltd. (Shanghai, China), and recrystallized from dry ethanol prior to use. Sodium azide $\left(\mathrm{NaN}_{3}\right)$ was purchased from Alfa Aesar Co., Ltd. Copper(II) sulfate pentahydrate $\left(\mathrm{CuSO}_{4} \cdot 5 \mathrm{H}_{2} \mathrm{O}\right), 1$,4-dioxane and dichloromethane $\left(\mathrm{CH}_{2} \mathrm{Cl}_{2}\right)$ were purchased from Sinopharm Chemical Reagent Co., Ltd. (Shanghai, China), dried and distilled prior to use. Other chemicals are all analytical reagents made in China and used without further purification.

\subsection{Synthesis of PNVCL- $\beta$-CD copolymers}

Alkynyl-terminated poly( $N$-vinylcaprolactam) (PNVCL-C $\equiv \mathrm{CH})$ and azido-terminated $\beta$-CD $\left(\mathrm{N}_{3}-\beta-\mathrm{CD}\right)$ were prepared by the method reported in the literature. ${ }^{\mathbf{4 3 4 4}}$ The PNVCL- $\beta$-CD copolymers were synthesized by click chemistry. $1.40 \mathrm{~g}$ PNVCL$\mathrm{C} \equiv \mathrm{CH}, 0.25 \mathrm{~g} \mathrm{~N}-\beta-\mathrm{CD}, 0.06 \mathrm{~g}(+)$-sodium ascorbate (SA), $0.03 \mathrm{~g}$ $\mathrm{CuSO}_{4} \cdot 5 \mathrm{H}_{2} \mathrm{O}$ and $85 \mathrm{~mL}$ mixed solvent $\left(t\right.$-butanol/DMF/ $/ \mathrm{H}_{2} \mathrm{O}=$ $3: 6: 8)$ were added into a round flask. The reaction was performed in an oil bath at $50{ }^{\circ} \mathrm{C}$ and terminated after $72 \mathrm{~h}$ under stirring. The mixture was concentrated and filtered. The filtrate was precipitated in acetone to give precipitate. The crude product was dissolved in water and precipitated in acetone twice, and then dried in vacuum at $40{ }^{\circ} \mathrm{C}$ for $24 \mathrm{~h}$ to give the desired PNVCL- $\beta$-CD copolymers as solid. The yield was approximately $60 \%$.

\subsection{Mineralization}

Gas diffusion method ${ }^{21}$ was used to perform the mineralization of $\mathrm{CaCO}_{3}$ in the presence of copolymers. Firstly, in a $50 \mathrm{~mL}$ bottle a certain amount of PNVCL- $\beta$-CD was dissolved in $10 \mathrm{~mL}$ deionized water (DIW). Then $\mathrm{CaCl}_{2}$ was added under mild stirring. The final solution volume was fixed at $20 \mathrm{~mL}$ by adding DIW. Glass slides were put into a $10 \mathrm{~mL}$ bottle containing $5 \mathrm{~mL}$ solution which was covered with parafilm punched 4 holes, and then the bottle was put into a closed desiccator where fresh $\left(\mathrm{NH}_{4}\right)_{2} \mathrm{CO}_{3}$ was used as the $\mathrm{CO}_{2}$ vapor source. All mineralization experiments were carried out at a constant temperature. For a certain time (typically $72 \mathrm{~h}$ ), the mixture was cooled to room temperature and the glass slides were removed from the solutions, rinsed with DIW, and then dried at room temperature for further analysis.

\subsection{Measurements}

Transmission electron microscopy (TEM) (JEM-2100 Japan JEOL Company) was used to investigated the morphology of the micelles, at an accelerating voltage of $80 \mathrm{kV}$. Specimens were prepared by transferring a drop of the micelle solution onto a 200 mesh copper grid coated with carbon and allowing the sample to dry in air before measurements. Scanning electron microscopy (SEM) (SU8010 Japan Hitachi Company) operated at an accelerating voltage of $10 \mathrm{kV}$ was employed to observe the samples on the glass slides after sputtered with gold. The polymorph of the sample was investigated by X-ray diffraction (XRD) (D8-Advance Germany Bruke Company) with $\mathrm{Cu}-\mathrm{K} \alpha$ radiation in the range $2 \theta=20-60^{\circ}$. Fourier Transform Infrared (FT-IR) spectra were recorded in transmission mode on a Spectra One FT-IR spectrometer (USA PE Company). Thermogravimetry analysis (TG) was carried out on a thermal analyzer (SDTQ600, USA TA Company). A Leici DDS-307 conductometer (Shanghai precision instrument Ltd.) was used to investigate the interactions between polymers and $\mathrm{Ca}^{2+}$ at a $\mathrm{Ca}^{2+}$ concentration of $20 \mathrm{mM}$. The morphology of samples in glass slides in the crystallization process was observed by an optical microscope (OM). The optical microscope micrographs were taken with an NIKON ECLIPSE 80i optical microscope (Japan Nikon Company).

\section{Results and discussion}

\subsection{Synthesis and characterization of PNVCL- $\beta-C D$}

The PNVCL- $\beta$-CD polymers were synthesized via alkyne-azide click reaction of PNVCL-C $\equiv \mathrm{CH}$ and $\mathrm{N}_{3}-\beta-\mathrm{CD}$. The FT-IR (Fig. S1 $\dagger$ ) and the ${ }^{1} \mathrm{H}$ NMR (Fig. S2 $\dagger$ ) spectra were used to confirm the structures of the PNVCL- $\beta$-CD block copolymers.

The GPC traces of the polymers are shown in Fig. S3. $\dagger$ Each sample showed a unimodal molecular weight distribution, indicating a successful synthesis of the copolymers. The PNVCL- $\beta$-CD polymers are denoted as PNVCL1- $\beta$-CD, PNVCL2$\beta-C D$ and PNVCL3- $\beta$-CD according to the varied molecular weights, respectively. Detailed information of the copolymers is showed in Table 1. 
Table 1 The characterization of PNVCL- $\beta-C D$ polymers

\begin{tabular}{lllll}
\hline Sample & NVCL$_{\text {TGA }}{ }^{a}$ & $M_{\mathrm{n}}{ }^{b}\left(\mathrm{~g} \mathrm{~mol}^{-1}\right)$ & PDI & CMC \\
\hline PNVCL1- $\beta$-CD & $25 / 1$ & 6289 & 1.07 & 0.33 \\
PNVCL2- $\beta$-CD & $35 / 1$ & 8374 & 1.13 & 0.11 \\
PNVCL3- $\beta$-CD & $45 / 1$ & 10400 & 1.04 & 0.07
\end{tabular}

${ }^{a}$ Molar ratio of NVCL to thioglycolic acid (TGA) in feed in synthesis of PNVCL-C $\equiv \mathrm{CH} .{ }^{b}$ Molar weight of copolymer determined by GPC in THF at $30^{\circ} \mathrm{C}$.

Fluorescence technique using pyrene as a probe (Fig. $\mathrm{S} 4 \dagger$ ) indicated that the PNVCL- $\beta$-CD could self-assemble into micelles at room temperature. The critical micelle concentrations (CMC) obtained from Fig. $55 \dagger$ are list in Table 1.

Fig. S6 $\dagger$ is a typical photograph of aqueous solutions of PNVCL2- $\beta$-CD, which showed a reversible LCST phase transition in water. Fig. $\mathrm{S} 7 \uparrow$ shows the temperature dependence of optical transmittance of micellar solutions of copolymers with different PNVCL block lengths. The LCST were evaluated as 39.7, 38.5, and $34.9{ }^{\circ} \mathrm{C}$ for PNVCL1- $\beta$-CD, PNVCL2- $\beta-C D$ and PNVCL3- $\beta-C D$, respectively, thus showing a decreasing trend with increasing PNVCL block length.

TEM were also used to investigate the thermosensitivity of the polymers (Fig. 1). At a temperature below the LCST $\left(25^{\circ} \mathrm{C}\right)$, the copolymer self-associated into micelles in water and the micelles existed individually with size of about $100 \mathrm{~nm}$. When the temperature was increased closed to the LCST $\left(40{ }^{\circ} \mathrm{C}\right)$, intermicelle aggregation resulted in formation of larger aggregates with multicore structure and associated. When the temperature continued to increase $\left(50^{\circ} \mathrm{C}\right)$, the aggregates collapsed due to the phase separation of the PNVCL block and more compact and regular structures with sizes of about $1 \mu \mathrm{m}$ were formed. Dynamic light scattering (DLS) showed the hydrodynamic diameter of the aggregates at $50{ }^{\circ} \mathrm{C}$ was 0.7 to $1.5 \mu \mathrm{m}$ (Fig. S8 $\dagger$ ), which was consistent with the TEM.

\section{2 $\mathrm{CaCO}_{3}$ crystallization in the presence of PNVCL- $\beta-\mathrm{CD}$ below the LCST}

When the solution temperature was below the LCST $\left(25^{\circ} \mathrm{C}\right)$, micelles was formed from the self-association of the copolymer and existed individually.
PNVCL2- $\beta$-CD was first presented as the additive of $\mathrm{CaCO}_{3}$ crystallization. The mineralizations were carried out in the polymer concentration from 0.01 to $2.0 \mathrm{~g} \mathrm{~L}^{-1}$ (Fig. 2) and fixed the concentration of $\mathrm{Ca}^{2+}$ at $20 \mathrm{mM}$.

In the presence of polymer concentration of $0.01,0.1,0.5$ and $1.0 \mathrm{~g} \mathrm{~L}^{-1}$, SEM indicated the obtained $\mathrm{CaCO}_{3}$ were typical rhombohedral calcite, which were very similar to the samples prepared without any additive. With increasing polymer concentration to $2.0 \mathrm{~g} \mathrm{~L}^{-1}$, the faces of the crystals were coarse. The increased polymer concentration could inhibit the motion of $\mathrm{Ca}^{2+}$, as well as the further growth of the crystals. The size of the calcite was ranging from several to $20 \mu \mathrm{m}$.

XRD and FT-IR measurements showed that the obtained crystals above are all mixtures of calcite and a small amount of aragonite (Fig. S9†).

The effects of PNVCL-C $\equiv \mathrm{CH}$ and $\beta$-CD homopolymers on the $\mathrm{CaCO}_{3}$ crystallization were investigated at $25{ }^{\circ} \mathrm{C}$. With $\mathrm{PNVCL}-\mathrm{C} \equiv \mathrm{CH}$ or $\beta-\mathrm{CD}$ as the additive respectively, the formed crystals exhibited a typical rhombohedral calcite (Fig. S10†), which was similar to the crystals formed without any additive (Fig. S10a †). The size of the calcite was ranging from 10 to $25 \mu \mathrm{m}$ at $25{ }^{\circ} \mathrm{C}$. These results indicate that PNVCL-C $\equiv \mathrm{CH}$ and $\beta$-CD individually have weak effects on $\mathrm{CaCO}_{3}$ mineralization at $25{ }^{\circ} \mathrm{C}$.

PNVCL- $\beta$-CD with different chain lengths may influence the morphology of $\mathrm{CaCO}_{3}$ crystal. Therefore, the effects of PNVCL1$\beta$-CD and PNVCL3- $\beta$-CD (Fig. 3) on the $\mathrm{CaCO}_{3}$ crystallization were studied. The crystals from PNVCL1- $\beta$-CD were an elongated morphology instead of traditional rhombohedral while those from PNVCL3- $\beta$-CD were calcite with some concaves on the surface. The size of the crystals kept unchanged.

\section{3 $\mathrm{CaCO}_{3}$ crystallization in the presence of PNVCL- $\beta$-CD above the LCST}

When the temperature was above the LCST $\left(50{ }^{\circ} \mathrm{C}\right)$, the PNVCL chains collapsed and the PNVCL- $\beta$-CD transformed into compact and regular aggregates with size of about $1.0 \mu \mathrm{m}$.

The effect of concentration of PNVCL2- $\beta$-CD on the mineralization was investigated by adjusting the polymer concentration from 0.01 to $2.0 \mathrm{~g} \mathrm{~L}^{-1}$ (Fig. 4) and fixing the concentration of $\mathrm{Ca}^{2+}$ at $20 \mathrm{mM}$.
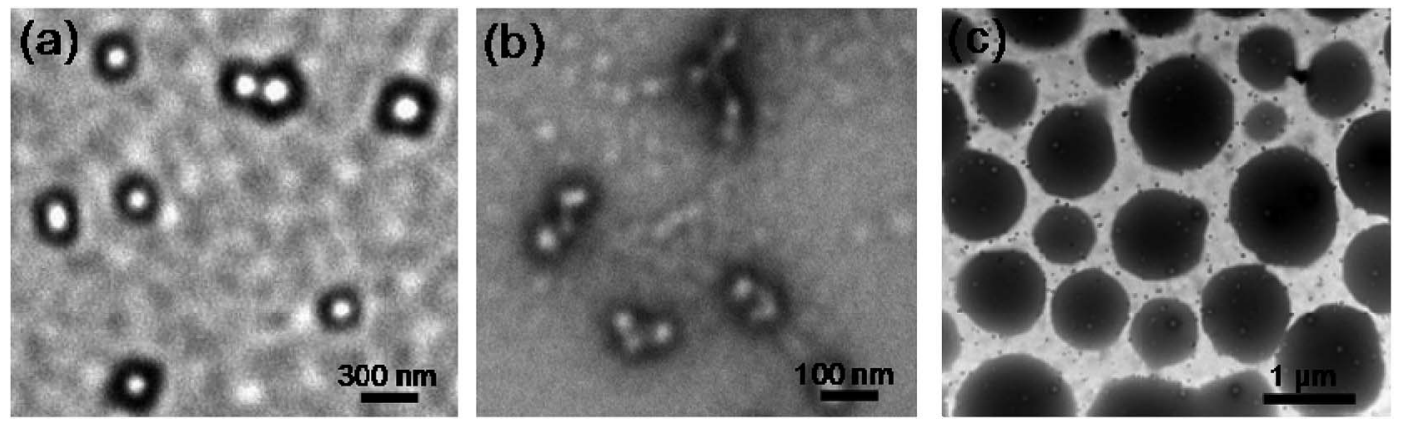

Fig. 1 TEM images of PNVCL2- $\beta-C D$ particles self-assembled in aqueous solution in different temperature. (a) $25^{\circ} \mathrm{C}$ (b) $40^{\circ} \mathrm{C}$ (c) $50{ }^{\circ} \mathrm{C}$. 

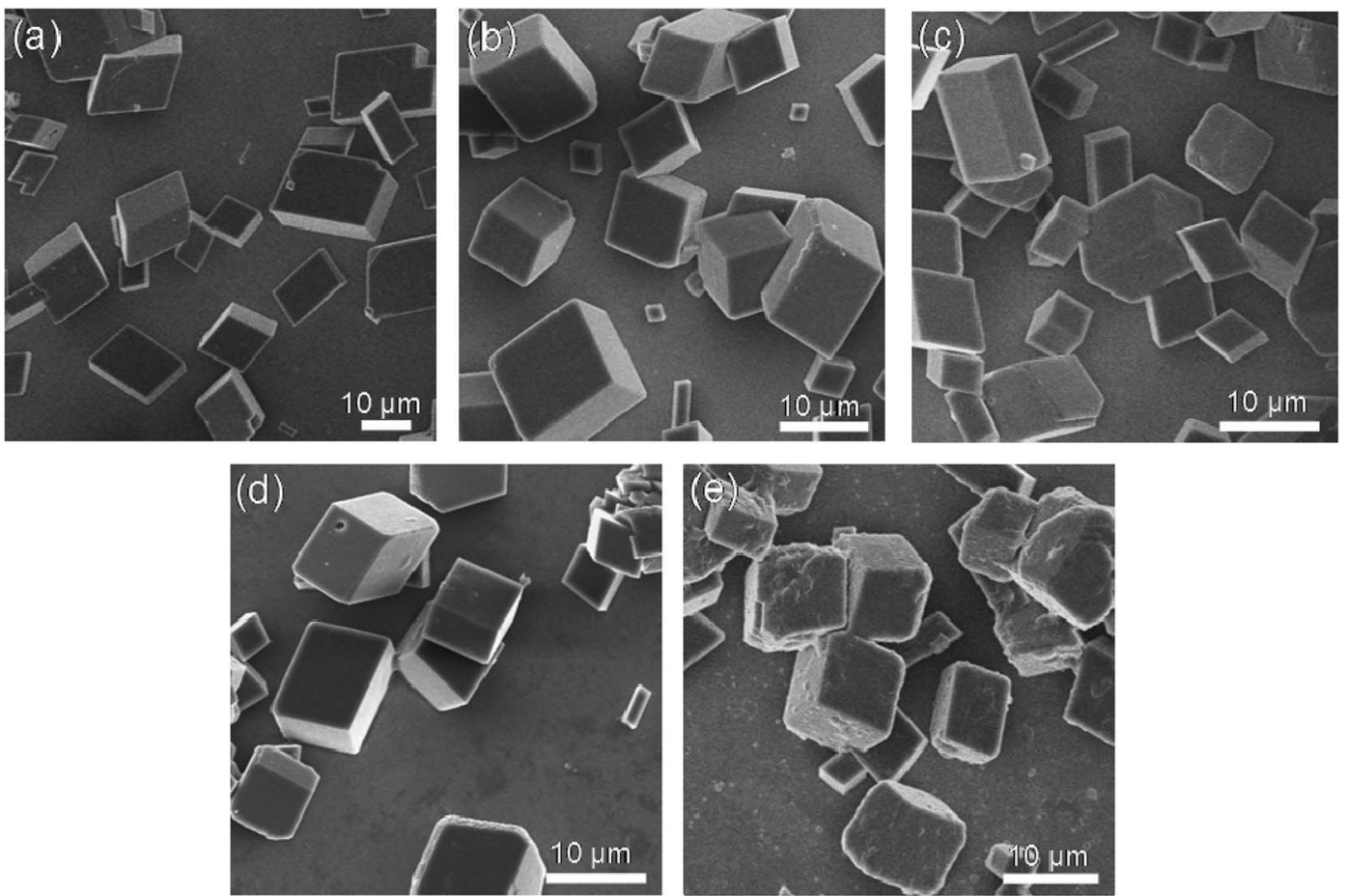

Fig. $2 \mathrm{SEM}$ images of $\mathrm{CaCO}_{3}$ crystals obtained in the presence of various PNVCL2- $\beta-\mathrm{CD}$ concentrations. (a) 0.01 , (b) 0.1 , (c) 0.5, (d) 1.0, (e) $2.0 \mathrm{~g} \mathrm{~L}^{-1}\left(\left[\mathrm{Ca}^{2+}\right]=20 \mathrm{mM}, T=25^{\circ} \mathrm{C}\right)$.

For all of the samples prepared, rhombohedral calcites were generated. When the concentrations were very low $(0.01,0.1$ and $\left.0.5 \mathrm{~g} \mathrm{~L}^{-1}\right)$, SEM was very similar to that prepared without any additive. When concentrations increased (1.0 and $\left.2.0 \mathrm{~g} \mathrm{~L}^{-1}\right)$, porous calcites were observed. The size of the calcite was ranging from 4 to $25 \mu \mathrm{m}$ with pores of $2-4 \mu \mathrm{m}$ for polymer concentration $1.0 \mathrm{~g} \mathrm{~L}^{-1}$ and 2 to $16 \mu \mathrm{m}$ with pores of $1-5 \mu \mathrm{m}$ for $2.0 \mathrm{~g} \mathrm{~L}^{-1}$. The porous calcites were just like cheeses.

XRD and FT-IR measurements showed that the aboveobtained crystals were all mixtures of calcite and a small amount aragonite.

The effects of PNVCL1- $\beta$-CD (Fig. 5a) and PNVCL3- $\beta$-CD (Fig. 5b) on the $\mathrm{CaCO}_{3}$ crystallization were also evaluated. The crystals are all porous calcite observed by SEM. XRD and FT-IR spectra demonstrated that they are calcite and a small amount of aragonite. The crystals from PNVCL1- $\beta$-CD were an elongated morphology while those from PNVCL3- $\beta$-CD with more pores compared with the sample formed from PNVCL2- $\beta$-CD. The size of the crystals and the pore of the three samples were about the same.

The effects of PNVCL-C $\equiv \mathrm{CH}$ homopolymers on the $\mathrm{CaCO}_{3}$ crystallization were examined at $50{ }^{\circ} \mathrm{C}$. With PNVCL-C $\equiv \mathrm{CH}$ as the additive, the formed crystal exhibited porous rhombohedral calcites (Fig. 5c). The size distribution of the pore is greatly uneven. Some pores were so large that the integrity of the calcite was destroyed.

These results indicate that PNVCL- $\beta$-CD may induce to form cheese-like porous $\mathrm{CaCO}_{3}$ crystals at $50{ }^{\circ} \mathrm{C}$.
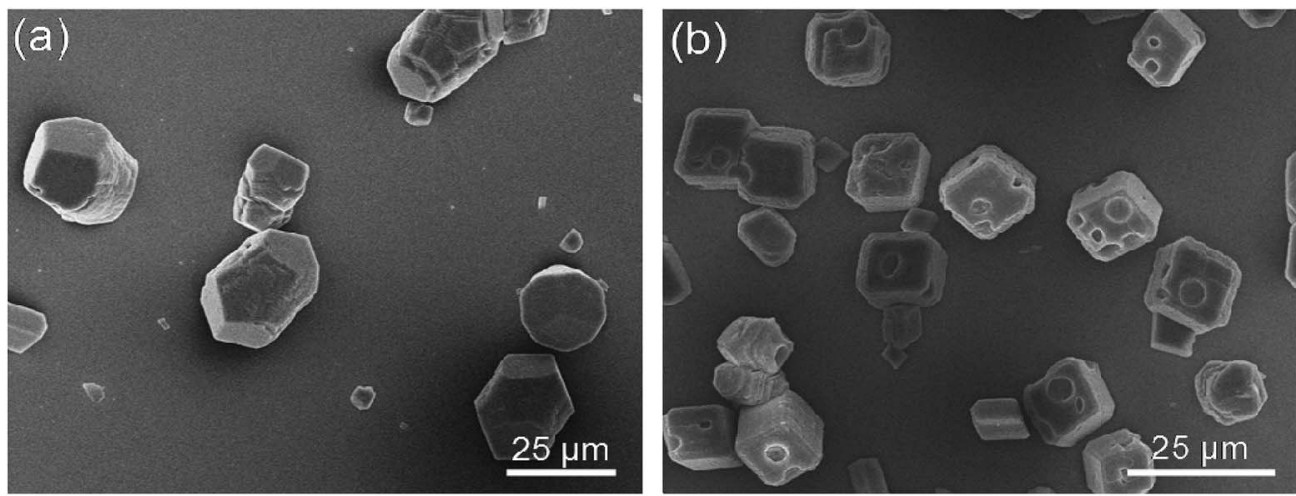

Fig. 3 SEM images of $\mathrm{CaCO}_{3}$ crystals obtained in the presence of PNVCL1- $\beta-C D(a)$ and PNVCL3- $\beta-C D(b)(C=1.0 \mathrm{~g} \mathrm{~L}-1)$. 

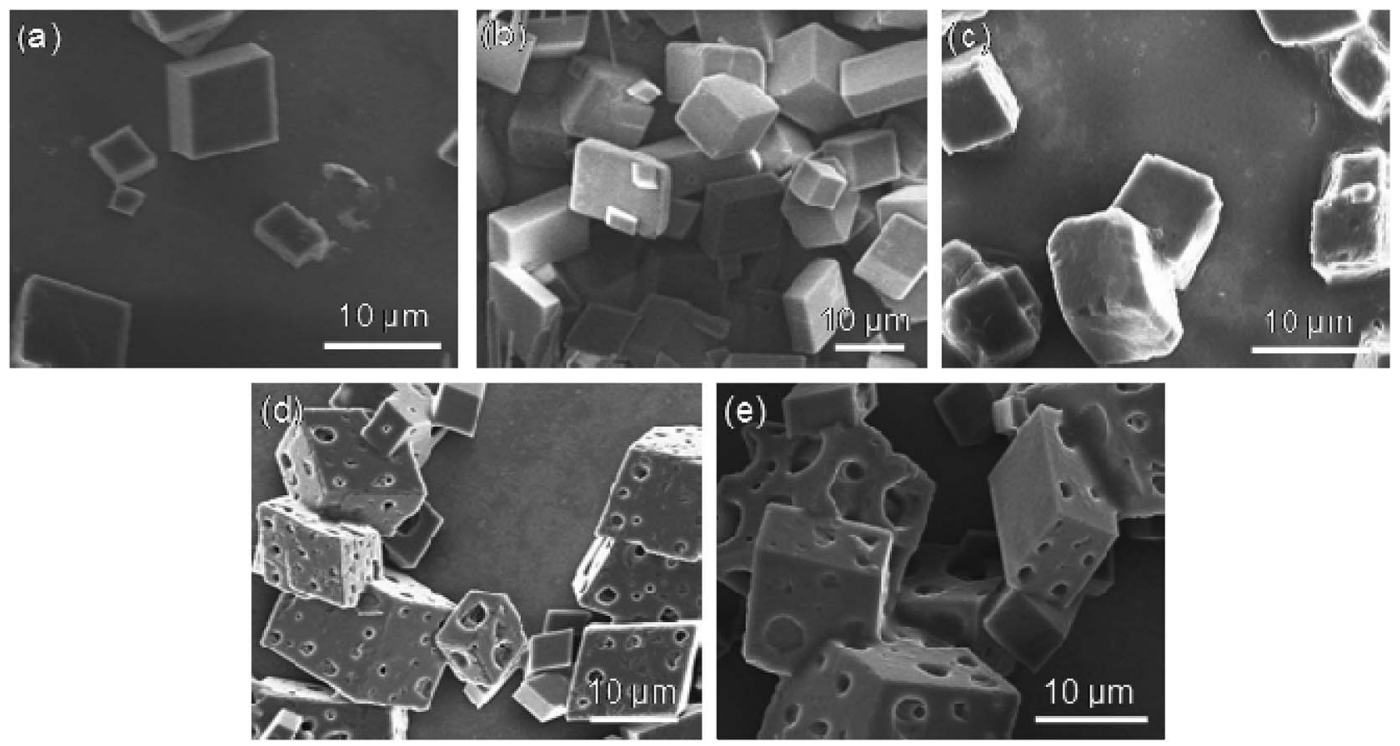

Fig. $4 \mathrm{SEM}$ images of $\mathrm{CaCO}_{3}$ crystals obtained in the presence of various PNVCL2- $\beta$-CD concentrations. (a) 0.01 , (b) 0.1, (c) 0.5, (d) 1.0, (e) $2.0 \mathrm{~g} \mathrm{~L}^{-1}\left(\left[\mathrm{Ca}^{2+}\right]=20 \mathrm{mM}, T=50^{\circ} \mathrm{C}\right)$.
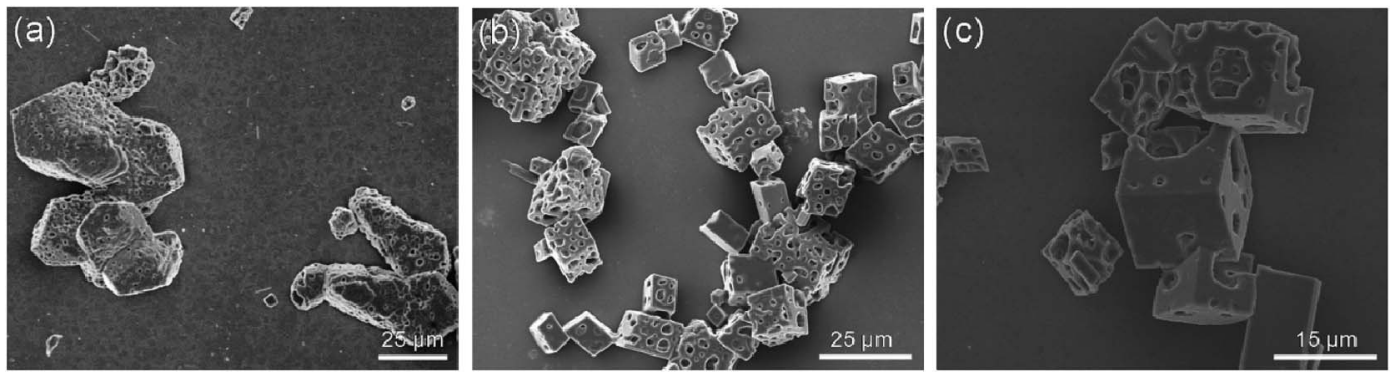

Fig. 5 SEM images of $\mathrm{CaCO}_{3}$ crystals obtained in the presence of PNVCL1- $\beta-C D(a), P N V C L 3-\beta-C D(b)$ and PNVCL-C $\equiv C H$ (c) ([Ca $\left.{ }^{2+}\right]=20$ mM, $T=50^{\circ} \mathrm{C}$

\subsection{Time-resolved experiment of the crystal formation in the} presence of PNVCL2- $\beta-C D$

To clarify the forming mechanism of the cheese-like crystal, the formation process was observed. The evolution of $\mathrm{CaCO}_{3}$ morphologies in the presence of $1.0 \mathrm{~g} \mathrm{~L}^{-1}$ PNVCL2- $\beta$-CD at $50{ }^{\circ} \mathrm{C}$ at different intervals is shown in Fig. 6. After $15 \mathrm{~min}$ crystallization, the optical image (Fig. 6a) indicated that there are a lot of mineral droplets with diameters of about $400 \mathrm{~nm}$. The wetting and coalescence behavior of the micro-droplet indicates the liquid-like character of the $\mathrm{CaCO}_{3}$ precursor. Since most droplets lack of birefringence in optical microscopy, we infer that they are amorphous calcium carbonate (ACC). A small amount of droplets shows birefringence character indicates that these precursors have partially crystallized (as indicated by the arrow), and the sizes of the particles have been increased compared with ACC droplets. After mineralization for $30 \mathrm{~min}$, with increasing of the population of ACC particles, aggregates with much larger size than ACC droplets were built (Fig. 6b). From the birefringence behavior of the formed aggregates, we deduced they are crystalline. After $1 \mathrm{~h}$ of reaction, porous crystals can be observed (Fig. 6c). The morphology is mainly cheese-like porous rhombohedral calcite after $2 \mathrm{~h}$ of reaction (Fig. 6d) and keeps substantially unchanged after $4 \mathrm{~h}$ of reaction (Fig. 6f). The cheese-like porous rhombohedral calcite then keeps unchanged to the final after $72 \mathrm{~h}$ of reaction. A polymer-induced liquid-precursor (PILP) phase existed in the mineralization system induced by PNVCL- $\beta$-CD as judged by the amorphous droplets at the initial reaction period. Compared with crystals formed in acidic polymer reported in ref. 27,28 the transformation from ACC to crystal is faster for PNVCL- $\beta$-CD, perhaps it is because the interaction between the polymer and $\mathrm{Ca}^{2+}$ is weaker.

\section{Mechanism study of the PNVCL- $\beta$ - CD controlled mineralization}

The PNVCL may have affinity for $\mathrm{Ca}^{2+}$ since it contains polar carbonyl group. A conductivity measurement was used to investigate the interaction between PNVCL2- $\beta$-CD and $\mathrm{Ca}^{2+}$ (Fig. 7) and to clarify the mechanism of cheese-like porous rhombohedral calcite formation. The conductivity of the polymer solution $\left(\Lambda_{\mathrm{PNVCL} 2-\beta-\mathrm{CD}}\right)$ and Ca-PNVCL2- $\beta$-CD hybrid 

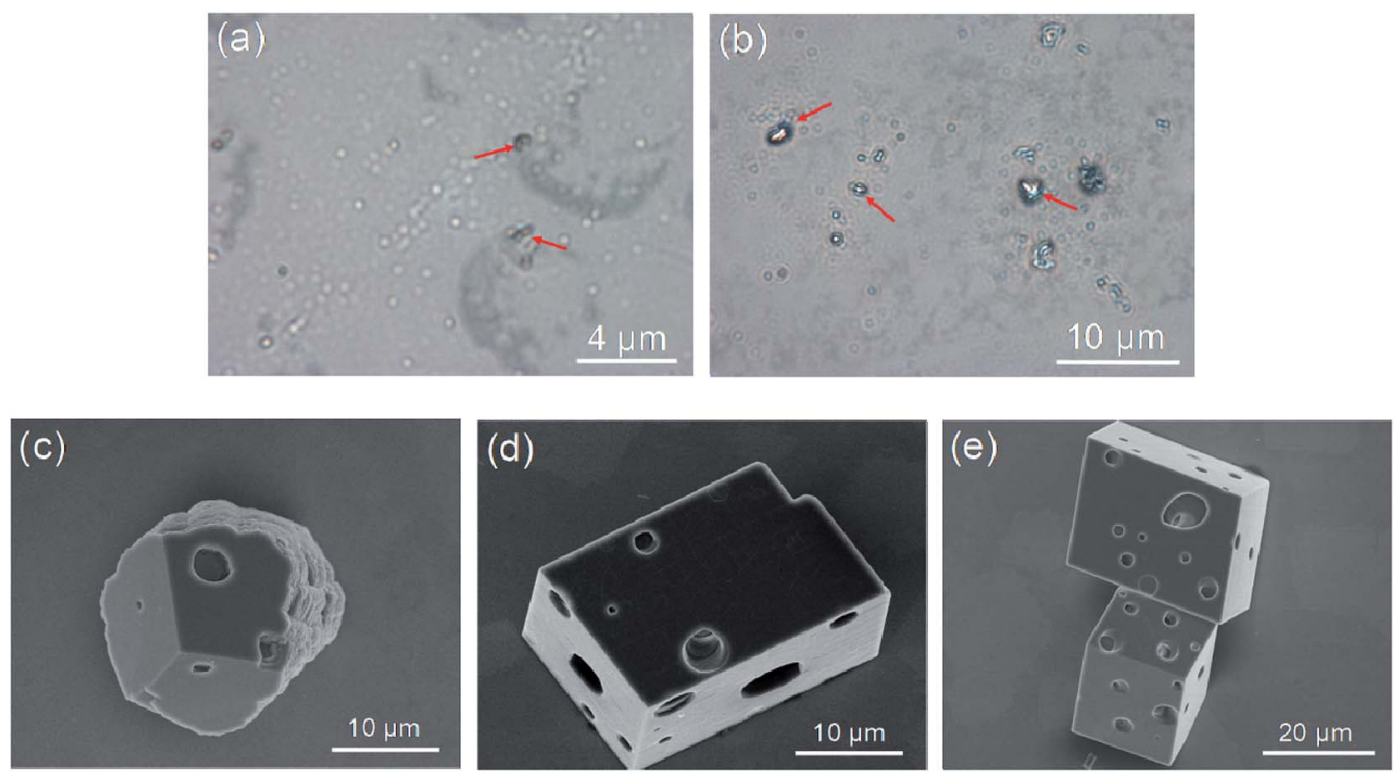

Fig. 6 The morphology evolution of cheese-like calcite crystals. Optical images of liquid precursors for 15 min (a) and 30 min (b) reaction. SEM

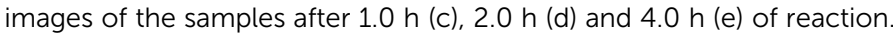

solution $\left(\Lambda_{\mathrm{Ca}-\mathrm{PNVCL} 2-\beta-\mathrm{CD}}\right)$ was recorded respectively. Increasing the polymer concentration makes the value of $\Lambda_{\mathrm{Ca}-\mathrm{PNVCL} 2-\beta-\mathrm{CD}}-\Lambda_{\mathrm{PNVCL} 2-\beta-\mathrm{CD}}$ decrease as the complexion of $\mathrm{Ca}^{2+}$ and PNVCL chains confines the free migration of $\mathrm{Ca}^{2+}$. The conductivities of PNVCL-C $\equiv \mathrm{CH}$ and $\beta$-CD solution were also measured respectively for comparison. For the PNVCL$\mathrm{C} \equiv \mathrm{CH}$ homopolymer, the changing trend of $\Lambda_{\mathrm{Ca}-\mathrm{PNVCL}}-\Lambda_{\mathrm{PNVCL}}$ is similar to that observed in PNVCL2- $\beta-\mathrm{CD} / \mathrm{CaCl}_{2}$ solution. The value of $\Lambda_{\mathrm{Ca}-\beta-\mathrm{CD}}-\Lambda_{\beta-\mathrm{CD}}$ keeps unchanged in the measuring concentration range of $0-2.0 \mathrm{~g} \mathrm{~L}^{-1}$, which implies the $\beta$-CD has inappreciable binding action for $\mathrm{Ca}^{2+}$. The results show that the PNVCL block of PNVCL- $\beta$-CD is the functional segment which attracts the $\mathrm{Ca}^{2+}$.

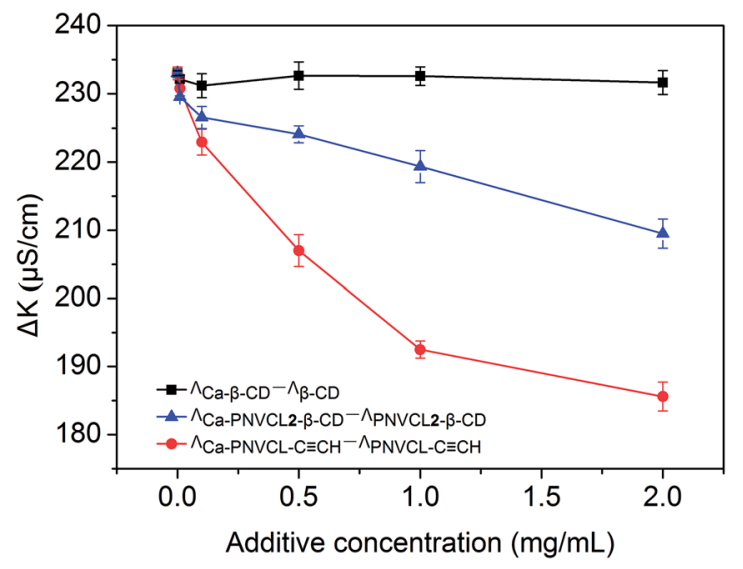

Fig. 7 The conductivity discrepancy curves of the additive and additive- $\mathrm{CaCl}_{2}$ hybrid solution on the basis of additive concentration. The $\Lambda_{\beta-\mathrm{CD}}, \Lambda_{\mathrm{PNVCL} 2-\beta-\mathrm{CD}}$ and $\Lambda_{\mathrm{PNVCL}-\mathrm{C} \equiv \mathrm{CH}}$ are conductivities of $\beta-\mathrm{CD}$, PNVCL2- $\beta-C D$ and PNVCL-C $\equiv \mathrm{CH}$. The $\Lambda_{\mathrm{Ca}-\beta-\mathrm{CD}}, \Lambda_{\mathrm{Ca}-\mathrm{PNVCL} 2-\beta-\mathrm{CD}}$ and $\Lambda_{\mathrm{Ca}-\mathrm{PNVCL}-\mathrm{C} \equiv \mathrm{CH}}$ are conductivities of $\beta-\mathrm{CD}, \mathrm{PNVCL} 2-\beta-\mathrm{CD}$ and $\mathrm{PNVCL}-\mathrm{C} \equiv \mathrm{CH}$ in the presence of $20 \mathrm{mM} \mathrm{Ca}^{2+}$.
The bind action of PNVCl to $\mathrm{Ca}^{2+}$ is weaker than that of acidic polymer chains due to the fluctuation of $\Lambda_{\mathrm{Ca}-\mathrm{PNVCL2}-\beta-\mathrm{CD}^{-}}$ $\Lambda_{\text {PNVCL2- } \beta \text {-CD }}$ with the variation of the PNVCL2- $\beta$-CD concentration is much smaller than that of acidic polymer chains in ref. 45. It is reasonable that the interaction between polar carbonyl group and $\mathrm{Ca}^{2+}$ is weaker than that between negatively charged $\mathrm{COO}^{-}$and $\mathrm{Ca}^{2+}$ and it is consistent with the timeresolved experiment.

Thermalgravimetric analysis (TG) shows the weight amount of polymers which is included in the crystals. As is shown in the sample of the $1.0 \mathrm{~g} \mathrm{~L}^{-1}$ polymer solution (Fig. 8a), the percent of remained PNVCL2- $\beta$-CD is about $1.83 \%$ by calculation (Fig. S11 $\dagger$ ). Also a lower weight loss is caused by lowering the PNVCL2- $\beta$-CD concentration. It can be concluded that the polymer shows great importance in the morphosynthesis of the crystals by the above results.

Based on the extensive experimental results, we concluded that the influences of PNVCL- $\beta$-CD on $\mathrm{CaCO}_{3}$ crystallization at the temperature below or above the LCST of PNVCL- $\beta$-CD are distinct.

At a temperature below the LCST, PNVCL was hydrophilic and the PNVCL2- $\beta$-CD aqueous solution was transparent. At initial stage, the $\mathrm{Ca}^{2+}$ should be on the surface of the micelles because of $\mathrm{Ca}^{2+}$ binding effect of the PNVCL. The decomposition of ammonium carbonate and subsequent diffusion of the $\mathrm{CO}_{2}$ into the solution initialed the mineralization of $\mathrm{CaCO}_{3}$, which was existed as ACC particles and temporarily stabilized against crystallization by binding to PNVCL- $\beta$-CD. The increasing of the ACC population and van der Waals forces among the ACC particles resulted in conglomerating of ACC particles. The polymer was encapsulated in the ACC when the particles conglomerated. After that, the crystallization of $\mathrm{CaCO}_{3}$ occurs in the ACC particles. Crystal growth is accomplished by the removal of solvent and/or the binding additives and the formation of interparticle chemical bonds. ${ }^{46}$ The binding effect 

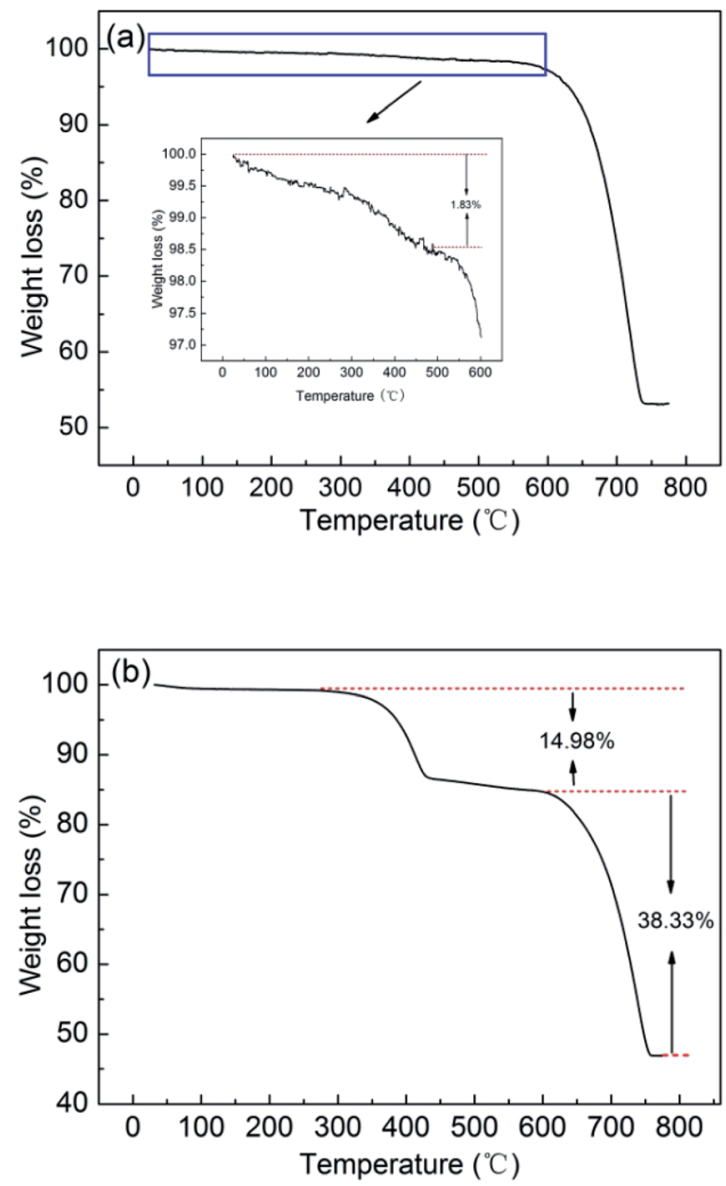

Fig. 8 TG curves of $\mathrm{CaCO}_{3}$ particles in PNVCL2- $\beta-C D$ solutions at $50{ }^{\circ} \mathrm{C}$ (a) and reined with hot water (b).

of PNVCL and $\mathrm{Ca}^{2+}$ is weak, so PNVCL- $\beta$-CD copolymers have weak effects on $\mathrm{CaCO}_{3}$ mineralization at $25^{\circ} \mathrm{C}$. The crystals were mainly rhombohedral calcite coexisting with a small amount of aragonite.
Water molecules in solution could be trapped in the hydrophobic cavity and be absorbed in the hydration shell of the $\beta$ $\mathrm{CD}$, resulting in volume occupancy of the $\beta$-CD segments. Therefore, the calcite units were limited to orienting along the crystallographic $c$-axis and fused together to minimize energy, leading to the formation of elongated morphology with a shorter PNVCL chain length of PNVCL1- $\beta$-CD (Fig. 3a). At a longer PNVCL chain length of PNVCL3- $\beta$-CD $\left(25^{\circ} \mathrm{C}\right)$, the migration of polymer was slower and thus some concaves were left on the surface of the sample (Fig. 3b).

When the temperature is above the LCST, PNVCL was hydrophobic and the copolymers aggregated into more compact and regular structures with sizes of about $1 \mu \mathrm{m}$. The copolymers aggregates stabilized the ACC precursor phase in the PILP system and aggregates-ACC were formed (Scheme 1a and b). The formation of aggregates-ACC can temporarily stabilized ACC droplets. The $\mathrm{CaCO}_{3}$ crystallization could be delayed for a period of time. The aggregates-ACC droplets coalesce solidify (Scheme 1c) with the increasing of the population. The mobility of the hydrophobic aggregates encapsulated in ACC is poor due to its poor solubility and most of them were still in $\mathrm{CaCO}_{3}$ crystals in the crystal growth process (Scheme 1d and e). They will became soluble and move out of the crystal when the reaction mixture cooling to room temperature, filtration and following rinsing. The removal of polymer aggregates resulted in the formation of pores (Scheme 1 and $g$ ). The size of the pore is a little larger than that of the polymer aggregate is due to an enlarged process after drying. We supposed that the polymer would remain in the sample if the reaction mixture kept at $50{ }^{\circ} \mathrm{C}$, followed by rinsing with hot water (about $50{ }^{\circ} \mathrm{C}$ ). It is confirmed by TG that the percent of remained PNVCL2- $\beta$-CD is calculated to be about $14.98 \%$ in the sample (Fig. $8 \mathrm{~b}$ ), which is a remarkable amount and close to the calcite prepared by Meldrum. ${ }^{47}$ The results showed that this is a method to incorporate organic additives within the crystals and then generate a composite material, introducing a characteristic texture and anisotropy into the crystal lattice. ${ }^{47}$

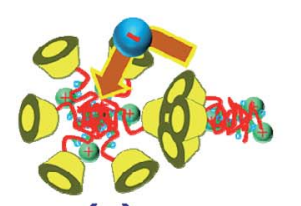

(a)

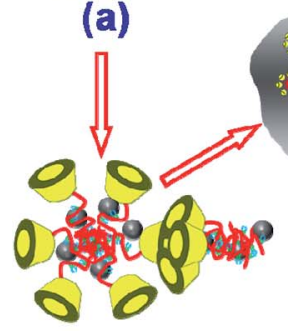

(b)

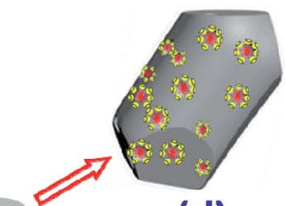

(d)

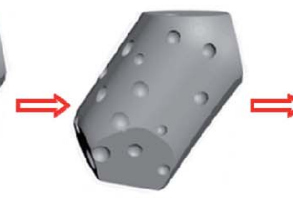

(f)

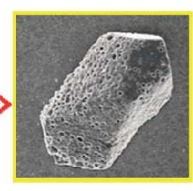

(1)

\section{$\oplus \mathrm{Ca}^{2+} \mathrm{CO}_{3}{ }^{2-} \mathrm{O} W \mathrm{PNVCL- \beta -CD}$ Amorphous particles}

Scheme 1 Scheme showing the growth mechanism of the $\mathrm{CaCO}_{3}$ crystals at $50{ }^{\circ} \mathrm{C}$. 
$\beta$-CD has a hydrophobic interiors. The primary and secondary hydroxyl groups render the outer surface of the molecule hydrophilic, making the $\beta$-CD water-soluble. ${ }^{28,48}$ The aggregates formed from PNVCL- $\beta$-CD at $50{ }^{\circ} \mathrm{C}$ possess relatively uniform sizes due to the hydrophilic $\beta-C D$, while PNVCL$\mathrm{C} \equiv \mathrm{CH}$ could form aggregates inhomogeneous in size and figure. The crystals modulated in PNVCL-C $\equiv \mathrm{CH}$ exhibit a porous rhombohedral calcite (Fig. $5 \mathrm{c}$ ), but the size of the pore is uneven and the calcite is not complete.

The results indicate that the PNVCL segment act as a functional block, while the $\beta-\mathrm{CD}$ act as a solubilizing segment. Furthermore, crystals from PNVCL-C $\equiv \mathrm{CH}$ and PNVCL2- $\beta$-CD controlled mineralization with different morphology imply that the $\beta$-CD plays a key role in the morphosynthesis of the minerals.

For PNVCL3- $\beta$-CD, the process was the same and resulted in porous crystals (Fig. 5b). And in the case of a shorter PNVCL chain length of PNVCL1- $\beta$-CD, the combination of PLIP process and the volume occupancy of the $\beta$-CD segments resulted in the formation of elongated porous morphology (Scheme 1f).

\section{Conclusions}

In the present work, a thermalsensitive polymer PNVCL- $\beta$-CD was synthesized and its unique influence on $\mathrm{CaCO}_{3}$ crystallization was studied. Below the LCST, the copolymer selfassembled into micelles and the micelles formed by copolymers with different PNVCL chain length mediated the formation of crystals with elongated, typical rhombohedral and surface concaved morphology. Above the LCST, the PNVCL was hydrophobic and the copolymers aggregated into more compact and regular structures with sizes of about $1 \mu \mathrm{m}$. The copolymer aggregates were encapsulated in the crystals and left after cooling and rinsing. The porous cheese-like crystals were obtained. The new findings from the experiments could provide us better understanding of the PILP as well as useful information for designing novel inorganic materials with porous structures.

\section{Conflicts of interest}

There are no conflicts to declare.

\section{Acknowledgements}

This work was financially supported by the Natural Science Foundation for Education Department of Liaoning Province of China (No. LYB201603).

\section{Notes and references}

1 L. Wang, Z. Meng, Y. Yu, Q. Meng and D. Chen, Polymer, 2008, 49, 1199-1210.

2 Y. Gao, S. Yu and X. Guo, Langmuir, 2006, 22, 6125-6129.

3 P. Zhang, X. Zhong, Y. Chai and Y. Liu, Colloid Polym. Sci., 2008, 286, 1135-1141.

4 H. Cölfen and L. Qi, Chem.-Eur. J., 2001, 7, 106-116.

5 S. Kumar, T. Ito, Y. Yanagihara, Y. Oaki, T. Nishimura and T. Kato, CrystEngComm, 2010, 12, 2021-2024.
6 K. Takahashi, A. Kobayashi, M. Doi, S. Adachi, T. Taguchi, T.-a. Okamura, H. Yamamoto and N. Ueyama, J. Mater. Chem., 2005, 15, 2178-2187.

7 A. S. Schenk, H. Zope, Y.-Y. Kim, A. Kros, N. A. J. M. Sommerdijk and F. C. Meldrum, Faraday Discuss., 2012, 159, 327-344.

8 D. Walsh, B. Lebeau and S. Mann, Adv. Mater., 1999, 30, 324-328.

9 D. Gebauer, H. Cölfen, A. Verch and M. Antonietti, Adv. Mater., 2009, 21, 435-439.

10 H. Cong and S. Yu, Cryst. Growth Des., 2009, 9, 210-217.

$11 \mathrm{X}$. Wei, Y. Su, T. Wen, Z. Li, J. Yang and D. Wang, CrystEngComm, 2013, 15, 3417-3422.

12 J. Yu, M. Lei, B. Cheng and X. Zhao, J. Solid State Chem., 2004, 177, 681-689.

13 J. Zhang, B. Yao, H. Ping, Z. Fu, Y. Li, W. Wang, H. Wang, Y. Wang, J. Zhang and F. Zhang, RSC Adv., 2016, 6, 472-480.

14 E. Mugnaioli, I. Andrusenko, T. Schuler, N. Loges, R. E. Dinnebier, M. Panthofer, W. Tremel and U. Kolb, Angew. Chem., Int. Ed., 2012, 51, 7041-7045.

$15 \mathrm{~A} . \mathrm{Xu}, \mathrm{M}$. Antonietti, S. H. Yu and C. Helmut, Adv. Mater., 2008, 20, 1333-1338.

16 A. Zhang, H. Xie, N. Liu, B. Chen, H. Ping, Z. Fu and B. Su, RSC Adv., 2016, 6, 110362-110366.

17 D. C. Popescu, M. M. J. Smulders, B. P. Pichon, N. Chebotareva, S. Y. Kwak, O. L. J. V. Asselen, R. P. Sijbesma, E. Dimasi and N. A. J. M. Sommerdijk, J. Am. Chem. Soc., 2007, 129, 1405814067.

18 Z. Xue, B. Hu, S. Dai, X. Jiang, S. Wu and Z. Du, Mater. Chem. Phys., 2011, 129, 315-321.

19 S. Champ, J. A. Dickinson, P. S. Fallon, B. R. Heywood and M. Mascal, Angew. Chem., Int. Ed., 2000, 43, 2716-2719.

20 Y. Xia, Y. Gu, X. Zhou, H. Xu, X. Zhao, M. Yaseen and J. R. Lu, Biomacromolecules, 2012, 13, 2299-2308.

21 S. Albeck, S. Weiner and L. Addadi, Chem.-Eur. J., 2010, 2, 278-284.

22 X. Wang, H. Sun, Y. Xia, C. Chen, H. Xu, H. Shan and J. R. Lu, J. Colloid Interface Sci., 2009, 332, 96-103.

23 C. Lu, L. Qi, H. Cong, X. Wang, J. Yang, L. Yang, D. Zhang, J. Ma and W. Cao, Chem. Mater., 2005, 17, 5218-5224.

24 H. Cölfen and M. Antonietti, Langmuir, 2007, 14, 582-589.

25 C. Cha, E. S. Kim, I. W. Kim and H. Kong, Biomaterials, 2011, 32, 2695-2703.

26 T. Wang, H. Cölfen and M. Antonietti, J. Am. Chem. Soc., 2005, 127, 3246-3247.

27 W. Zhu, J. Lin and C. Cai, J. Mater. Chem., 2012, 22, 3939-3947.

28 R. Kurapati and A. M. Raichur, J. Mater. Chem. B, 2013, 1, 3175-3184.

29 Y. Liu, W. Yuan, Y. Shi, X. Chen, Y. Wang, H. Chen and H. Li, Angew. Chem., Int. Ed., 2014, 53, 4127-4131.

30 F. Yan, C. Guo, X. Zhang and G. Yuan, CrystEngComm, 2012, 14, 2046-2052.

31 F. Yan, C. Guo, X. Zhang and G. Yuan, CrystEngComm, 2012, 14, 1554-1560.

32 D. Gebauer, X. Liu, B. Aziz, N. Hedin and Z. Zhao, CrystEngComm, 2013, 15, 1257-1263.

33 B. Wang, P. Prinsen, H. Wang, Z. Bai, H. Wang, R. Luque and J. Xuan, Chem. Soc. Rev., 2017, 46, 855-914. 
34 M. Abebe, N. Hedin and Z. Bacsik, Cryst. Growth Des., 2015, 15, 3609-3616.

35 N. B. J. Hetherington, A. N. Kulak, Y. Kim, E. H. Noel, D. Snoswell, M. Butler and F. C. Meldrum, Adv. Funct. Mater., 2011, 21, 948-954.

36 C. Li and L. Qi, Angew. Chem., 2008, 120, 2422-2427.

37 A. Pich, A. Tessier, V. Boyko, Y. Lu and H. J. P. Adler, Macromolecules, 2006, 39, 7701-7707.

38 A. Laukkanen, F. M. Winnik and H. Tenhu, Macromolecules, 2005, 38, 2439-2448.

39 S. Sun and P. Wu, J. Phys. Chem. B, 2011, 115, 11609-11618.

40 G. R. Deen, E. K. Lim, C. H. Mah and K. M. Heng, Ind. Eng. Chem. Res., 2012, 51, 13354-13365.

41 Y. Maeda, A. Tomoya Nakamura and I. Ikeda, Macromolecules, 2002, 35, 217-222.
42 M. L. Bender and M. Komiyama, Cyclodextrin Chemistry, Springer, 1979.

43 Q. Wu, J. Yi, Z. Yin, S. Wang, Q. Yang, S. Wu, X. Song and G. Zhang, J. Polym. Res., 2013, 20, 262-270.

44 G. Zhang, F. Liang, X. Song, D. Liu, M. Li and Q. Wu, Carbohydr. Polym., 2010, 80, 885-890.

45 W. Zhu, J. Lin, C. Cai and Y. Lu, J. Mater. Chem. B, 2013, 1, 841-849.

46 R. L. Penn, J. Phys. Chem. B, 2004, 108, 12707-12712.

47 Y. Kim, K. Ganesan, P. Yang, A. N. Kulak, S. Borukhin, S. Pechook, L. Ribeiro, R. Kröger, S. J. Eichhorn, S. P. Armes, B. Pokroy and F. C. Meldrum, Nat. Mater., 2011, 10, 890-896. 48 F. B. D. Sousa, A. C. Lima, Â. M. L. Denadai, C. P. A. Anconi, W. B. D. Almeida, W. T. G. Novato, H. F. D. Santos, C. L. Drum, R. Langer and R. D. Sinisterra, Phys. Chem. Chem. Phys., 2012, 14, 1934-1944. 